\title{
Free and Protein-bound Maillard Reaction Products in Beer: Method Development and a Survey of Different Beer \\ Types
}

Michael Hellwig, Sophia Witte, Thomas Henle

Chair of Food Chemistry, Technische Universität Dresden, D-01062 Dresden, Germany

Corresponding author:

T. Henle

Tel.: +49-351-463-34647

Fax: $+49-351-463-34138$

Email: Thomas.Henle@chemie.tu-dresden.de

-Supporting information- 


\begin{tabular}{c|c|c|c|c|c|}
\hline FL & ML & PYR & FOM & MAL MGH1 \\
\hline 0.51 & -0.26 & 0.38 & 0.45 & 0.52 & 0.51 \\
$*$ & n.s. & n.s. & n.s. & $*$ & $*$ \\
\hline
\end{tabular}

Figure S1. Correlations between free and protein-bound concentrations of Maillard reaction products. Spearman's rang correlation coefficients $\left(r_{S}\right)$ and significance of correlations were calculated using the software PASW Statistics 18. n.s., not significant $(P>0.01)$. *, significant $(P<0.01)$. FL, fructosyllysine; ML, maltulosyllysine; PYR, pyrraline; FOM, formyline; MAL, maltosine; MG-H1, methylglyoxal-derived hydroimidazolone 1; APY, argpyrimidine.

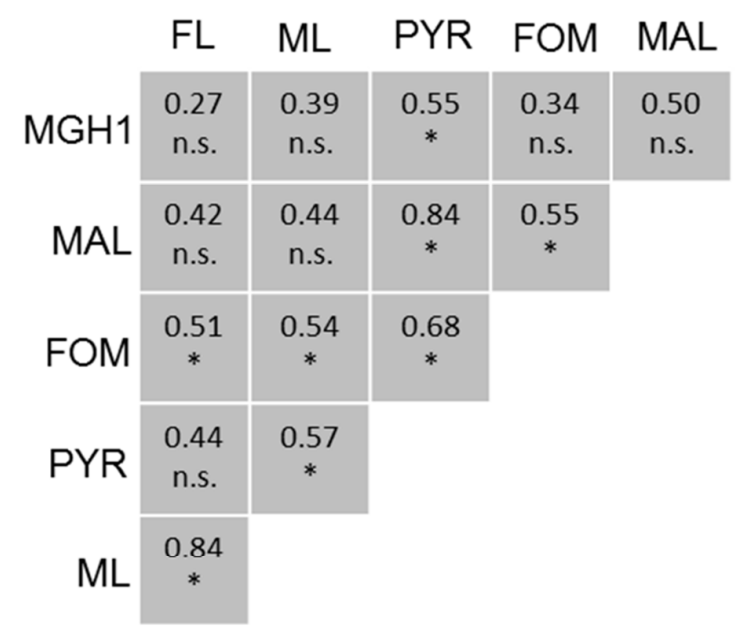

Figure S2. Correlations between individual protein-bound Maillard reaction products. Statistical details and abbreviations, see Figure S1.

\begin{tabular}{|c|c|c|c|c|c|c|c|}
\hline & $\mathrm{FL}$ & $\mathrm{ML}$ & PYR & FOM & MAL & MGH1 & APY \\
\hline free & $\begin{array}{c}0.49 \\
\text { n.s. }\end{array}$ & $\begin{array}{c}0.15 \\
\text { n.s. }\end{array}$ & $\begin{array}{c}0.60 \\
*\end{array}$ & $\begin{array}{c}0.43 \\
\text { n.s. }\end{array}$ & $\begin{array}{c}0.36 \\
\text { n.s. }\end{array}$ & $\begin{array}{c}0.50 \\
\text { n.s. }\end{array}$ & $\begin{array}{c}0.49 \\
\text { n.s. }\end{array}$ \\
\hline protein-bound & $\begin{array}{c}0.50 \\
\text { n.s. }\end{array}$ & $\begin{array}{c}0.40 \\
\text { n.s. }\end{array}$ & $\begin{array}{c}0.40 \\
\text { n.s. }\end{array}$ & $\begin{array}{c}0.20 \\
\text { n.s. }\end{array}$ & $\begin{array}{c}0.40 \\
\text { n.s. }\end{array}$ & $\begin{array}{c}0.27 \\
\text { n.s. }\end{array}$ & n.a. \\
\hline
\end{tabular}

Figure S3. Correlations between color and free and protein-bound concentrations of Maillard reaction products. Statistical details and abbreviations, see Figure S1. n.a., not analyzed. 